\title{
Uma análise de escritas reflexivas de licenciandos em Matemática
}

\author{
An analysis of reflective writings of undergraduate mathematics \\ students
}

\section{Un análisis de los escritos reflexivos de los estudiantes de Matemáticas}

\author{
Francielle Silva Gardin (fran.gardin@ @otmail.com) \\ Universidade Estadual de Londrina - UEL \\ Edilaine Regina dos Santos (edilaine.santos@yahoo.com.br) \\ Universidade Estadual de Londrina - UEL
}

\begin{abstract}
Resumo: Neste artigo tem-se por objetivo apresentar alguns resultados de uma investigação realizada em torno da temática da escrita reflexiva, que teve como uma de suas intencionalidades analisar escritas reflexivas de futuros professores de Matemática. Foram analisadas produções de estudantes da Licenciatura em Matemática da Universidade Estadual de Londrina, produzidas no $1^{\circ}$ bimestre de 2019 e relacionadas a um trabalho em torno das Operações Aritméticas. Por meio desta investigação, foi possível identificar alguns aspectos que podem contribuir para o processo de formação docente: expressão de sentimentos, estabelecimento de relações entre o que já se tinha conhecimento e o que aprendeu, planejamento de estratégias diferentes após reflexão sobre determinada situação.
\end{abstract}

Palavras-chave: Educação Matemática; Formação de Professores de Matemática; Caderno de aula com reflexões.

Abstract: This article aims to present some results of an investigation carried out on reflective writing. One of the objectives of this research was to analyse preservice mathematics teachers' reflective writings. We analysed reflective writings of mathematics teaching degree students at the State University of Londrina, produced in the first two months of 2019 and related to work about arithmetic operations. Through this research, we identified some aspects that can contribute to the teacher education process: expression of feelings, the establishment of relationships between what was already known and what was learned, planning different strategies after reflecting on a specific situation.

Keywords: Mathematics Education; Mathematics Teacher Education; Class notebook with reflections.

Resumen: Este artículo tiene como objetivo presentar algunos resultados de una investigación realizada en torno al tema de la escritura reflexiva, que tuvo como una de sus intenciones analizar los escritos reflexivos de los futuros profesores de Matemáticas. Se analizaron las producciones de futuros profesores de Matemáticas, realizadas en 2019 y relacionadas con un

Recebido em: 29/01/2021

Aceite em: 28/07/2021 
trabajo sobre Operaciones Aritméticas. Se pudo identificar algunos aspectos que pueden contribuir al proceso de formación docente: expresión de sentimientos, establecimiento de relaciones entre lo ya conocido y lo aprendido, planificando diferentes estrategias luego de reflexionar sobre una determinada situación.

Palabras-clave: Educación Matemática; Formación de profesores de matemáticas; Cuaderno de reflexión.

\section{INTRODUÇÃO}

A utilização de escrita reflexiva, por meio de diferentes instrumentos, no âmbito da formação inicial de professores tem sido considerada como potencializadora para o processo de formar-se professor (GALIAZZI; LINDEMANN, 2003; PASSOS, 2008; FIORAVANTE, 2014; SILVA; PASSOS, 2016).

Um dos motivos para essa consideração é a de que quando escrevemos "[...] nos colocamos na posição de aprendentes, na medida em que refletimos sobre o caminho trilhado, sobre as dúvidas, limitações e aprendizagens construídas com os diversos sujeitos que participam desse caminhar." (FIORAVANTE, 2014, p. 26).

Outro motivo é o de que "A escrita reflexiva sobre a prática docente é muito importante para a formação do professor, pois a escrita ajuda na reflexão da atividade realizada e/ou a ser realizada pelos futuros professores [...]" (UHMANN, 2019, p.265).

Neste artigo, tem-se por objetivo apresentar alguns resultados de uma investigação realizada em torno dessa temática e que teve como uma de suas intencionalidades analisar escritas reflexivas de futuros professores de Matemática.

Para isso, em um primeiro momento são apresentadas considerações a respeito dos pressupostos teóricos que fundamentaram a investigação. Na sequência, os procedimentos metodológicos adotados, seguido das análises realizadas. Por fim, algumas considerações.

\section{ESCRITA REFLEXIVA: ALGUNS PRESSUPOSTOS TEÓRICOS}

De um modo geral, pode-se entender uma escrita reflexiva como uma escrita mais pessoal se comparada a outros tipos de escrita acadêmica, pois permite que o autor expresse sentimentos e concepções sobre determinado assunto. Entretanto, isso não "[...] significa despejar tudo o que você pensa e sente de uma maneira totalmente desestruturada. Uma escrita reflexiva requer uma linha de pensamento clara, uso de evidências ou exemplos para

Recebido em: 29/01/2021

Aceite em: 28/07/2021 
ilustrar suas reflexões e uma abordagem analítica." (UNIVERSITY OF BIRMINGHAM, 2015, p. 6, Tradução nossa).

Hampton (2010) apresenta uma estrutura possível para o desenvolvimento de uma escrita reflexiva. Em geral, pode constituir-se de uma descrição (o que aconteceu e/ou está sendo examinado?), interpretação (o que é mais importante/relevante sobre o objeto, evento ou ideia? Como se pode explicar algo com teoria? No que se assemelha ou difere de outros?) e resultado (o que aprendi? O que isso significa para o futuro?).

Pesquisas acerca da utilização desse tipo de escrita com professores e futuros professores revelam potencialidades que favorecem o processo de aprendizagem daqueles que a propõem e/ou daqueles que a realizam (GALIAZZI; LINDEMANN, 2003; PASSOS, 2008; MINÉ, 2011; PONTES, 2011; FIORAVANTE, 2014). Uma das potencialidades diz respeito à oportunidade de aprendizagem acerca de conteúdos matemáticos e de conhecimentos teóricos e práticos relacionados à prática docente.

Ao utilizar diários reflexivos, Passos (2008, p. 34) afirma que na formação de professores é “[...] uma das práticas formativas que ampliam a visão sobre o que deve saber o professor de matemática para ingressar com sucesso na profissão". Por meio dos diários reflexivos, a autora apresenta que identificou a intenção dos licenciandos, após presenciarem a realidade da sala de aula, de superar a prática de uma comunicação tímida e com pouca disposição de promover aprendizagens nas aulas de Matemática. Afirma, ainda, que os diários reflexivos "[...] revelaram conhecimentos da base de conhecimento para o ensino, evidenciando compreensões, conhecimentos, habilidades e disposições necessárias para exercer sua futura profissão.” (PASSOS, 2008, p. 34).

No trabalho de Pontes (2011) também é possível observar aspectos de oportunidade de aprendizagem acerca de conhecimentos teóricos e práticos por meio de escritas reflexivas. A autora apresenta que os registros reflexivos constituíram, para os participantes de sua pesquisa, espaço para teorização das práticas, possibilitando construir e reconstruir experiências e articular teoria, prática e autoria.

Na pesquisa de Fioravante (2014) esse aspecto também é evidenciado. A autora apresenta que a escrita possibilita

[...] não apenas o registrar/documentar, mas o pensar e com tal movimento aprender [...]. [...]. A escrita pode subsidiar a construção de seus conhecimentos teóricopráticos, uma vez que se parte dela como possibilidade de organizar o pensamento e

Recebido em: 29/01/2021

Aceite em: 28/07/2021 
qualificar cada vez mais argumentos que nos auxiliam a pensar sobre ações a partir da compreensão do vivido. (FIORAVANTE, 2014, p. 23-24).

A autora afirma ainda que "[...] experiências são registradas, podendo ser pensadas e ressignificadas, contribuindo assim para a reflexão na formação de professores, valorizando o profissional que pensa sobre a própria prática.” (FIORAVANTE, 2014, p. 81).

Outro aspecto a ser destacado como potencial a partir de escritas reflexivas é a possibilidade de se estabelecer um diálogo entre formadores e futuros professores. A pesquisa de Galiazzi e Lindemann (2003), por exemplo, que aborda possibilidades de aprendizagem acerca de ser professor, a partir da utilização de diários reflexivos com alunos em situação de estágio, destaca o potencial para a construção de um professor reflexivo, uma vez que, por meio da escrita reflexiva nesse instrumento, o licenciando pode estabelecer um diálogo com seus docentes e consigo mesmo e, com esses diálogos, construir conhecimentos mais fundamentados. Ainda, relatam que, diante de situações desestabilizadoras, a escrita, possibilita desabafo e amparo.

Em relação a esse aspecto do diálogo, Radetzke (2018, p.12) afirma que

[...] a escrita como mero mecanismo de registro/descrição pouco ou nada contribui para o processo formativo e (re) constitutivo da prática do Ser Professor. No entanto ao abarcar os desafios, possibilidades, reflexões e relações entre Professor e alunos no compartilhar de experiências, permite um diálogo reflexivo e constitutivo da prática pedagógica (RADETZKE, 2018, p.12).

Outra potencialidade está relacionada à possibilidade de uma análise sobre a prática por parte daqueles que escrevem reflexivamente. A partir disso, Fioravante (2014, p. 26), por exemplo, afirma que "Ao dialogar consigo e com sua prática, os professores em formação encontram também a possibilidade de questionar a realidade em que estão inseridos, buscando maneiras de transformá-las sempre que exista a necessidade.”

Pode-se perceber que escrever reflexivamente pode contribuir com o processo de formar-se professor. Atrelada a diferentes instrumentos, pode oportunizar aprendizagem de conteúdo matemático e de conhecimentos teóricos e práticos acerca da prática docente; oportunizar também diálogo entre formadores e futuros professores, além de uma análise da própria prática e, com isso, a busca de mudanças com o propósito de aperfeiçoamento sempre que houver necessidade.

\section{PROCEDIMENTOS METODOLÓGICOS}

Recebido em: 29/01/2021

Aceite em: 28/07/2021 
Para a constituição do corpus da pesquisa foram utilizadas escritas reflexivas de três estudantes ${ }^{1}$ do $3^{\circ}$ ano da Licenciatura em Matemática da Universidade Estadual de Londrina (UEL), produzidas no $1^{\circ}$ bimestre letivo de 2019 no contexto de uma disciplina de Prática e Metodologia do Ensino da Matemática ${ }^{2}$ a respeito do conteúdo "Operações Aritméticas" (adição, subtração, multiplicação e divisão), mais especificamente a respeito da resolução e explicação de procedimentos realizados para o cálculo das seguintes operações aritméticas com números naturais:

\begin{tabular}{|cccc|}
\hline $4283+514$ & $3456+795$ & $786-23$ & $601-417$ \\
$452 \times 13$ & $769 \times 102$ & $842 \div 2$ & $1515 \div 15$ \\
\hline
\end{tabular}

Fonte: Notas de aula do professor da disciplina

Figura 1 - Operações aritméticas utilizadas no trabalho com os licenciandos

O trabalho com os futuros professores foi realizado do seguinte modo: em um primeiro momento tiveram que resolver, individualmente, as operações propostas e explicar os procedimentos utilizados. Posteriormente, algumas aulas foram destinadas para que esses estudantes, em pequenos grupos, resolvessem apenas uma das operações, utilizando argumentos matemáticos adequados para explicar a operação a alunos do $6^{\circ}$ ano do Ensino Fundamental. Nesse momento, os futuros professores poderiam utilizar livros didáticos disponibilizados em sala durante as aulas e, também, alguns materiais de estudo enviados por e-mail pelo professor da disciplina. Depois, nas últimas aulas do bimestre, esses pequenos grupos realizaram apresentações para a turma, em que foram propostas discussões de aspectos conceituais e pedagógicos.

As escritas sobre esse trabalho foram produzidas em um instrumento denominado Caderno de Aula com Reflexões, que diz respeito ao caderno constituído por registros escritos acerca dos assuntos abordados nas aulas, seguidos de uma reflexão posterior para cada uma, e que pode conter descrição de algo ou algum episódio transcorrido em aula que tenha chamado atenção e provocado certa reflexão a respeito e, a partir disso, uma análise de tal fato

\footnotetext{
${ }^{1} \mathrm{O}$ critério para a seleção de três estudantes foi considerar as escritas reflexivas, de acordo com a ficha de avaliação do professor responsável pela disciplina, produzidas em todos os dias de trabalho com o conteúdo "Operações Aritméticas". Os alunos selecionados aceitaram participar da pesquisa assinando o Termo de Consentimento Livre e Esclarecido.

${ }^{2}$ Escolhida em virtude de ser uma disciplina do âmbito da Educação Matemática e possibilitar a abordagem de conteúdos Matemáticos da Educação Básica e aspectos pedagógicos para o ensino desses conteúdos.
}

Recebido em: 29/01/2021

Aceite em: 28/07/2021 
cuidadosamente, podendo destacar o significado disso para a formação ou aprendizagem profissional.

A fim de preservar o anonimato dos futuros professores que aceitaram participar dessa pesquisa e garantir que não sofram qualquer tipo de constrangimento, serão identificados nesse artigo por FP1, FP2 e FP3. O código utilizado contém a sigla FP, que significa "futuro professor" seguido de um algarismo para diferenciar os participantes.

De um modo geral, as análises foram realizadas tendo em vista alguns procedimentos da Análise da Produção Escrita em Matemática (SANTOS, 2014; SANTOS, BURIASCO, 2015, 2016), tais como leitura vertical e leitura horizontal. Uma leitura vertical, que significa proceder uma leitura de todas as produções de um mesmo participante, foi realizada com o intuito de conhecer a sequência de ideias e de trabalho com as operações aritméticas de cada um. Já a leitura horizontal, que diz respeito a uma leitura das produções de todos os participantes para um mesmo dia de aula, foi realizada na busca de entender como os licenciandos, de um modo geral, trabalharam com o que lhes foi proposto. Na seção seguinte são apresentadas algumas análises que foram realizadas considerando o procedimento de leitura horizontal.

\section{ANÁLISE DO MATERIAL}

Nesse artigo é apresentado um recorte das análises realizadas. Para isso, optou-se em expor nessa seção as análises em torno das escritas reflexivas dos futuros professores referente ao primeiro dia de trabalho em grupo e ao último dia de apresentações.

As primeiras análises apresentadas são referentes ao primeiro dia de trabalho em pequenos grupos. Cada grupo deveria realizar um estudo de uma das operações básicas propostas, buscando explicar a operação pela qual havia ficado responsável, utilizando argumentos matemáticos adequados para alunos do $6^{\circ}$ ano do Ensino Fundamental.

A primeira escrita ${ }^{3}$ apresentada é a do Futuro Professor 1 (FP1) referente ao primeiro dia de trabalho em grupo.

Na aula de hoje foi formado um grupo para cada conta da semana passada, meu grupo ficou com a última, 1515 $\div 15$. Isso aconteceu pois agora devemos, com auxílio de materiais didáticos, explicar/ensinar como fazer essa conta para alunos

\footnotetext{
${ }^{3}$ Para esse artigo foram realizadas transcrições das escritas dos licenciados, de modo que fossem apresentadas tal como os futuros professores as produziram.
}

Recebido em: 29/01/2021

Aceite em: 28/07/2021 
do $6^{\circ}$ ano. Tivemos essa aula para pesquisar sobre, e se não bastasse eu achar dificil escrever os passos que eu utilizei agora tenho que parar para pensar realmente o porquê das coisas, dos procedimentos e, ainda, imaginar possíveis dúvidas que os alunos tenham. Ou seja, devo estar preparada para responder perguntas sobre as coisas que eu faço na mat., devo me preparar e estudar mais (neste estilo).

Descobri, ou talvez tenha relembrado, como dividir por subtrações sucessivas $e$ usando proporcionalidade. O mais triste (momento desabafo) é que minha memória é fraca, então talvez daqui a um mês eu já nem lembre como posso fazer uma conta de divisão por outros métodos.

Nessa produção, ao escrever que "[...] agora tenho que parar para pensar realmente o por quê das coisas, dos procedimentos e, ainda, imaginar possíveis dúvidas que os alunos tenham", é possível identificar uma oportunidade de aprendizagem desse futuro professor sobre a prática docente, no que diz respeito à ampliação da visão sobre o que o professor deve saber (PASSOS, 2008).

Ainda, nessa escrita observa-se um “[...] (momento desabafo) [...]”, em que o estudante escreve que sua memória é fraca e que, possivelmente, após um tempo terá esquecido como realizar a operação de divisão através de outros métodos que não o algoritmo convencional. Nesse trecho é possível identificar um desabafo por parte do licenciando, o que segundo Galiazzi e Lindemann (2003), é oportunizado pela escrita. Esse registro permite, também, identificar uma expressão de sentimentos, se referindo com tristeza sobre a situação, o que caracteriza a escrita reflexiva como um tipo de escrita mais pessoal (HAMPTON, 2010).

O próximo registro foi produzido por FP2 também para o primeiro dia de trabalho em grupo.

Nesta aula nós continuamos a trabalhar com as operações básicas, as mesmas na aula anterior, porém agora, cada grupo trabalhou uma operação. Antes nós tínhamos que efetuar e explicar as operações do jeito que sabiamos fazer, agora temos que formular uma explicação como se estivessemos explicando para um aluno do $6^{\circ}$ ano do ensino fundamental, usando argumentos $e$ linguagens adequados.

Bem, no começo eu fiquei meio perdida, pois nosso grupo ficou com a operação 8 , de divisão, justamente a que tive dificuldade em explicar o porquê de colocar um zero na chave para baixar dois números seguidos, mas depois eu pensei em explicar a operação pelo método das subtrações sucessivas (nem sabia que tinha um nome) pelo qual eu não precisaria explicar essa questão. Entretanto, a $\mathrm{LI}^{4}$ me explicou o porquê do zero, é tão simples que me senti meio burra de não ter enxergado. Colocar o zero, nada mais é do que trabalhar com qualquer outro número, faz parte da operação, por exemplo:

\footnotetext{
${ }^{4}$ Código utilizado para indicar a menção de outro licenciando dessa disciplina.
}

Recebido em: 29/01/2021

Aceite em: 28/07/2021 


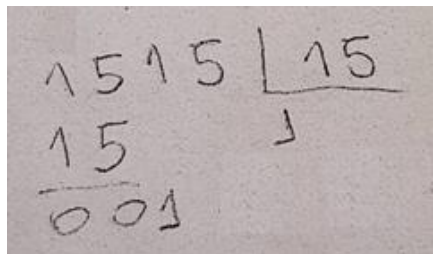

Qual número inteiro que multiplicado por 15 resulta em 1? Não tem, mas o mais próximo é o zero.

Eu me pergunto: por que ensinam a gente a colocar um zero como se ele tivesse caido de paraquedas ali no meio, sendo que, na verdade, ele faz parte normalmente da conta?

Enfim, optamos por explicar os dois métodos: o algoritimo tradicional e o método das subtrações sucessivas. $O$ primeiro, devo confessar, que não participei do desenvolvimento, fiquei tentando baixar os arquivos e testando o segundo método, quando vi eles já tinham feito, porém ainda nos restou uma dúvida "qual explicação que se dá para a divisão começar pela unidade de milhar (neste caso) e não pela unidade como nas outras operações?", vamos pensar nisso na próxima aula. Já o segundo método eu me propus a fazer, já que não participei do primeiro. Para mim, nesse método o aluno tem menos chance de errar, pois ele pode fazer aproximações. Contúdo, fico pensando se da certo ensinar os dois métodos, se os alunos não iriam fazer confusão. É mais uma dúvida. Temos a proxima aula para terminar.

Portanto, nesta aula, nós estudamos argumentos matemáticos para explicar os processos mecânicos e buscamos uma forma de explicar de forma adequada para que os alunos aprendam sem matemágica.

Nessa escrita, é possível identificar um aspecto que indica oportunidade de aprendizagem de conhecimento matemático quando o licenciando escreve: "Colocar o zero, nada mais é do que trabalhar com qualquer outro número, faz parte da operação [...]. Qual o número que multiplicado por 15 resulta em 1? Não tem, mas o mais próximo é o zero". Podese observar que o futuro professor escreve uma explicação que o ajudou a compreender o processo de divisão utilizando o algoritmo convencional da divisão, estabelecendo uma relação com o cálculo apresentado, o que segundo Miné (2011) constitui o processo de construção de conhecimentos matemáticos.

Outro aspecto possível de identificar é a oportunidade de expressão de sentimentos e concepções desse licenciando quando escreve: “[...] é tão simples que me senti meio burra de não ter enxergado". Esse trecho indica a expressão de uma indignação acerca do conhecimento desse conteúdo matemático, um desabafo diante de certa situação que, segundo Galiazzi e Lindemann (2003), é um aspecto que pode ser oportunizado por meio da escrita.

Ainda, é possível identificar o aspecto de diálogo consigo mesmo no trecho: "Eu me pergunto: Por que ensinam a gente a colocar um zero como se ele tivesse caído de paraquedas ali no meio, sendo que, na verdade, ele faz parte normalmente da conta?". Galiazzi e Lindemann (2003) escrevem sobre a oportunidade de se construir um professor mais reflexivo e conhecimentos mais fundamentados, a partir do diálogo com professor e consigo mesmo, potencializado por meio da escrita.

Recebido em: 29/01/2021

Aceite em: 28/07/2021 
Nesse mesmo trecho há indícios, também, de uma análise sobre a prática docente. Há um questionar da realidade em que se encontra (FIORAVANTE, 2014), um questionar sobre o ensino, ao que indica pouco significativo em termos de justificativas, em relação à realização da operação de divisão.

No penúltimo parágrafo dessa escrita, o futuro professor menciona que acredita na possibilidade de menos erros na divisão, utilizando o método das subtrações sucessivas, isso porque esse método permite fazer aproximações. Aqui é possível observar indício de expressão de teoria pessoal (GALIAZZI; LINDEMANN, 2003). Ao relacionar o método com a possibilidade de menos erros, o estudante pode estar associando com possíveis êxitos de experiência pessoal utilizando tal método.

Na sequência apresenta um questionamento sobre o surgimento de dúvidas, para os alunos, ao aprender dois métodos: "Contudo, fico pensando se da certo ensinar os dois métodos, se os alunos não iriam fazer confusão. É mais uma dúvida”. Nesse fragmento identifica-se indício de oportunidade de aprendizagem acerca da prática docente, uma vez que são apresentadas reflexões por meio da escrita que, segundo Fioravante (2014), oportuniza

[...] o pensar e com tal movimento aprender [...]. [...]. A escrita pode subsidiar a construção de seus conhecimentos teórico-práticos, uma vez que se parte dela como possibilidade de organizar o pensamento e qualificar cada vez mais argumentos que nos auxiliam a pensar sobre ações a partir da compreensão do vivido. (FIORAVANTE, 2014, p. 23-24).

Na sequência é apresentada a escrita reflexiva de FP3 para o primeiro dia de trabalho em grupo.

Na última aula foi proposto um trabalho em dupla. No qual cada dupla ficou responsável por uma operação, onde devíamos resolvê-lá de modo claro e explícito visando que explicaríamos tal resolução para uma criança.

A princípio nos pareceu uma atividade "simples". Porém, pelo contrário! Tornouse algo bem complexo. Afinal, como explicar uma operação básica, no nosso caso a divisão, para quem nunca estudou ou viu nada sobre? Por que todas as operações iniciam-se pela casa da unidade, à direita, enquanto só a divisão começa pela esquerda? O que é divisor, dividendo, quociente e resto? Pra que serve a divisão? Estas foram algumas das perguntas que nos surgiu. Tentamos, então, respondê-las!

Achei essa dinâmica de aula bem interessante e bastante objetiva. Pude me dedicar a entender um pouco mais sobre questões acerca da educação básica. Tais como, "por que divisão? Pra que divisão? Como resolver?" Questões estas que dificilmente eu parei pra pensar.

No excerto: “A princípio nos pareceu uma atividade 'simples'. Porém, pelo contrário! Tornou-se algo bem complexo", é possível observar uma expressão de desapontamento ao

Recebido em: 29/01/2021

Aceite em: 28/07/2021 
escrever sobre sua percepção inicial e posterior ao desenvolvimento da atividade. A expressão desse sentimento pode ser caracterizada como um desabafo, conforme Galiazzi e Lindemann (2003).

Na sequência do trecho mencionado acima, são apresentadas as questões: “[...]. Afinal, como explicar uma operação básica, no nosso caso a divisão, para quem nunca estudou ou viu nada sobre? Por que todas as operações iniciam-se pela casa da unidade, à direita, enquanto só a divisão começa pela esquerda? O que é divisor, dividendo, quociente e resto? Para que serve a divisão? [...]" e o indicativo de uma busca para resolvê-las. Segundo Semana e Santos (2008), refletir sobre a aprendizagem, identificar dificuldades e propor estratégia para melhoria fazem parte do processo de autorregulação das aprendizagens.

No último parágrafo dessa escrita reflexiva, FP3 menciona que, por meio da tarefa proposta, pôde se "[...] dedicar a entender um pouco mais sobre questões acerca da educação básica. Tais como, 'por que divisão? Pra que divisão? Como resolver?' Questões estas que dificilmente eu parei pra pensar". Esse excerto indica oportunidade de construção de conhecimentos matemáticos (MINÉ, 2011), nesse caso relacionados à operação de divisão.

Ainda, é possível identificar indícios de uma análise sobre a prática, uma vez que questiona a realidade em que se encontra e se busca maneiras de transformá-la (FIORAVANTE, 2014). O estudante pode ter buscado uma transformação da realidade quando aponta ter se dedicado a compreender questões que, antes, dificilmente o faziam pensar sobre.

As escritas reflexivas apresentadas na sequência são referentes ao último dia de trabalho com as operações aritméticas. Nessa aula finalizaram-se as apresentações dos grupos. O primeiro registro analisado foi produzido por FP1.

Na aula de hoje foi apresentada as últimas 3 apresentações, sendo a última do meu grupo, a $1^{a}$ foi uma multiplicação em que foi falado dos "nomes" dos números multiplicados e das respostas das multiplicações em uma mesma conta, algo que eu não sabia. Observei também nas falas e notações no quadro em que nós muitas vezes não explicamos, algo que me pondo no lugar de um aluno do $6^{\circ}$ ano talvez. ficaria com dúvidas, ou seja, devo prestar mais atenção no que eu falo. E sobre a divisão o $1^{o}$ grupo falou bastante coisa do que planejavamos falar, então foi mais tranquilo de apresentar, apesar do nervosismo kkk. 
Em relação a multiplicação, acredito que inicialmente seja mais fácil para os alunos entenderem fazendo com a soma do resultado de todas as multiplicações individualmente, como o L1 apresentou.

A escrita reflexiva de FP1 apresenta indício de aprendizagem de conteúdo matemático (MINÉ, 2011) quando o estudante relata sobre um dos grupos ter apresentado os elementos da multiplicação e aponta que era algo desconhecido anteriormente por ele.

Outro aspecto possível de ser identificado nesse registro, diz respeito à aprendizagem de aspectos acerca da prática docente, quando relata ter observado falas e notações que podem não ser esclarecedoras para alunos de $6^{\circ}$ ano, e enfatizar sobre ter mais atenção com o que se fala. Nesse trecho, o licenciando destaca a necessidade de uma explicação clara, por parte do professor, para evitar dúvidas aos alunos. Esse aspecto tem relação com ampliar a visão sobre o que o professor deve saber (PASSOS, 2008).

Ainda, esse mesmo aspecto é possível de ser identificado ao fim dessa produção, em que FP1 apresenta que a utilização de um método de resolução da operação de multiplicação, diferente do convencional, pode auxiliar a compreensão dos alunos em um primeiro momento.

A produção a seguir é a de FP2 para o último dia de trabalho com as operações aritméticas.

Nesta aula continuaram as apresentações, desta vez foi uma apresentação de multiplicação e duas de divisão.

Em relação a multiplicação, como a operação era entre duas centenas, o grupo dividiu a operação em outras três multiplicações. Para mim, foi interessante, mas levantaram a questão de que para trabalhar no $6^{\circ}$ ano que é nosso foco, não seria muito interessante justamente por transformar uma operação em outras três operações. Entretanto, foi apresentado outro método menos complexo que ajudou a justificar o algoritmo convencional, que foi o seguinte:

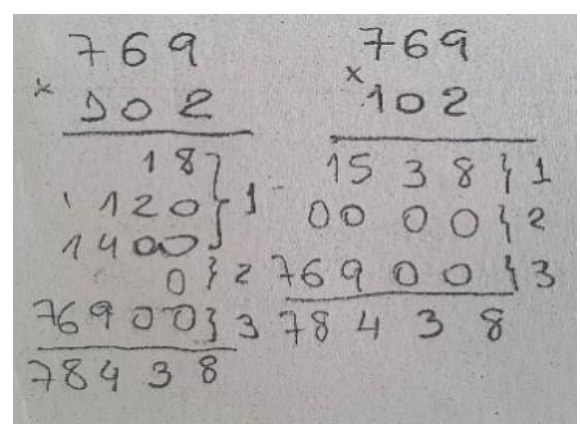

Acho que seria útil fazer essa comparação na hora de trabalhar com os alunos.

Quanto a divisão, como era nossa operação, não teve muitas novidades, mas aprendi e entendi muita coisa durante os estudos, por exemplo, o significado de colocar o 0 para poder 'abaixar' dois números seguidos e que é possível resolver da direita para esquerda. Além disso, percebi a importância de utilizar as classes e as

Recebido em: 29/01/2021

Aceite em: 28/07/2021 
ordens para a explicação da operação.

Portanto, essa atividade das operações básicas foi muito importante, pois me fez. refletir sobre os métodos e entender melhor na hora de trabalhar com os alunos. Adorei!

Essa escrita apresenta indícios de aprendizagem de conteúdo quando aponta, no segundo parágrafo, um método que pode auxiliar na justificativa do algoritmo convencional da multiplicação e estabelece relações entre dois algoritmos. Segundo Miné (2011), a construção de conhecimentos matemáticos acontece quando se estabelecem relações através da escrita.

Ainda no trecho em que discorre sobre a multiplicação, identificam-se indícios de oportunidade de aprendizagem de aspectos relacionados à prática docente, quando o licenciando relata sobre a utilidade de se abordar diferentes métodos de resolução com os alunos. Isso indica qualificação de argumentos que "[...] auxiliam a pensar sobre ações a partir da compreensão do vivido" (FIORAVANTE, 2014, p. 24), nesse caso, a ação de articular os registros para justificar a utilização do algoritmo convencional.

Por fim, ao escrever sobre a operação de divisão, o estudante relata que não teve muita novidade com a apresentação, isso porque já havia estudado essa operação nas aulas anteriores, mas enfatiza que os estudos realizados proporcionaram aprendizagem referente a essa operação.

O último registro apresentado nessa seção foi produzido por FP3.

A partir desses 9 grupos, foi possível conhecer, estudar e aprender muitas e variadas maneiras de se ensinar, aprender e abordar as 4 operações básicas.

Foi muito claro e convincente que não há maneiras únicas de se resolver as operações, $e$ que não se sabe todas as maneiras porque não é ensinado, porque não é convencional, porque não há tempo, porque os professores não sabem todas (e isso não é uma crítica! Ninguém precisa saber tudo).

Quando foi proposto trabalhar com as operações básicas, confesso que passou pela minha cabeça que era algo simples. Não é nada simples! Não é fácil! Não há uma única maneira de se abordar! Não é nada básico. Afinal, as operações básicas são bases para as demais.

Gostei muito dessa proposta de aula, aprendi termos corretos, maneiras diversas de se solucionar operações, sanei dúvidas, aprendi a me pôr no lugar do aluno e no lugar do professor. Além disso, tive a oportunidade de conhecer diferentes ideias, ponto de vista, dúvidas e posicionamentos. Foi tudo muito válido e enriquecedor.

Ainda, com base na minha operação, acredito que aprendi muito, descobri maneiras novas de resolver a divisão, tal como a convencional (da maior ordem para a menor ordem), da menor ordem para maior ordem e das subtrações sucessivas. Acredito também que poderia e posso melhorar minha apresentação, utilizando termos corretos e coerentes. Além de explicar com clareza e sutileza, afinal quem está aprendendo não tem obrigação de acompanhar passo a passo o que uma pessoa com maior tempo de prática sabe.

Recebido em: 29/01/2021

Aceite em: 28/07/2021 
Essa escrita apresenta indícios de que houve aprendizagem de conteúdo matemático, acerca das quatro operações básicas, e de aspectos relacionados à prática docente: “A partir desses 9 grupos, foi possível conhecer, estudar e aprender muitas e variadas maneiras de se ensinar, aprender e abordar as 4 operações básicas."

Ao relatar que "Quando foi proposto trabalhar com as operações básicas, confesso que passou pela minha cabeça que era algo simples. Não é nada simples! Não é fácil! Não há uma única maneira de se abordar! Não é nada básico", identifica-se indício de um desabafo, uma crítica sobre seu percurso (GALIAZZI; LINDEMANN, 2003).

Ainda, o penúltimo parágrafo dessa escrita apresenta indícios de aprendizagem de conhecimentos de conteúdos, ao relatar sobre termos corretos, diferentes possibilidades de resolução das operações e diferentes ideias dessas operações, infere-se que pode haver aprendizagem de conhecimentos teóricos acerca de conteúdos. Além disso, ao relatar que aprendeu a se colocar no lugar de professor, é possível observar indícios de aprendizagem de conhecimentos acerca da prática docente.

No último parágrafo dessa produção, a escrita sobre a aprendizagem de novas maneiras de efetuar a operação de divisão, indica que pode ter ocorrido uma nova aprendizagem de conhecimento teórico acerca do conteúdo. No trecho: "Acredito também que poderia e posso melhorar minha apresentação, utilizando termos corretos e coerentes. Além de explicar com clareza e sutileza [...]", é possível identificar indícios de autorregulação das aprendizagens. Faz-se inferência de uma autoavaliação, em que se critica o próprio percurso, toma consciência de seus erros e propõe estratégias para superá-los. Segundo Gomes (2008), a autorregulação acontece quando o aluno critica seu próprio percurso e procura formas de se autocorrigir.

\section{ALGUMAS CONSIDERAÇÕES}

Neste artigo, teve-se por objetivo apresentar alguns resultados de uma investigação realizada em torno da temática da escrita reflexiva e que teve como uma de suas intencionalidades analisar escritas reflexivas de futuros professores de Matemática.

Por meio da investigação realizada, pode-se observar a recorrência da apresentação de uma breve descrição do acontecido em aula, contextualizando o assunto a ser discorrido. Nesse tipo de escrita, a descrição da situação que subsidia a reflexão apresenta-se como aspecto pertinente, tanto para as pessoas que se propõem a realizar leituras desses registros,

Recebido em: 29/01/2021

Aceite em: 28/07/2021 
uma vez que pode auxiliar em sua compreensão, quanto para os que a realizam, pois “[...] a descrição constitui-se em alimento para o registro reflexivo, oferecendo subsídios para pensar sobre a própria prática, avaliando o trabalho e projetando os próximos passos a serem planejados.” (FIORAVANTE, 2014, p. 90).

Outra característica possível de ser observada, diz respeito à escrita reflexiva ser mais pessoal, se comparada a outros tipos de escrita. Quando se escreve reflexivamente, o futuro professor, por exemplo, pode dissertar sobre um objeto, evento ou ideia que tenha sido relevante para si, podendo expressar seus sentimentos. Essa característica pode ser observada em todas as escritas reflexivas analisadas, evidenciada, principalmente, por meio da utilização de pronomes pessoais na primeira pessoa.

Foi possível identificar, também, que as escritas reflexivas dos futuros professores permeiam a constatação e/ou superação de alguma dificuldade, ou aprendizagens referentes a conteúdos matemáticos e prática docente. Esse aspecto vai ao encontro de que uma escrita reflexiva oportuniza a manifestação de uma análise sobre a própria prática ou habilidade, com a finalidade de aprimoramento e aprendizagem.

Ao escrever reflexivamente, os futuros professores puderam expressar sentimentos, de angústia, de indignação ou de satisfação, estabelecer relações entre o que se já tinha conhecimento e o que se aprendeu ou, ainda, traçar estratégias diferentes após refletir sobre determinada situação. Aspectos tais como esses, mobilizados por meio de uma escrita reflexiva, podem contribuir para a formação de um professor reflexivo e na construção de conhecimentos relacionados a conteúdos de ensino e a prática docente.

\section{REFERÊNCIAS BIBLIOGRÁFICAS}

FIORAVANTE, Ana Paula Gonçalves. Escrita reflexiva na formação inicial de professores: vivências no curso de pedagogia da FURG. 2014. 115 f. Dissertação (Mestrado em Educação) - Programa de Pós-Graduação em Educação, Universidade Federal do Rio Grande, Rio Grande, 2014.

GALIAZZI, Maria do Carmo; LINDEMANN, Renata Hemandez. O diário de estágio: da reflexão pela escrita para a aprendizagem sobre ser professor. Olhar de professor. Ponta Grossa, v. 6, n. 1, p. 135-150, 2003.

GOMES, Anabela. Auto-avaliação das aprendizagens dos alunos e investimento na apropriação de critérios de avaliação. In: MENEZES Luís; SANTOS, Leonor; GOMES, Helena; RODRIGUES, Cátia (org.). Avaliação em Matemática: Problemas e desafios. 1. ed.

Recebido em: 29/01/2021

Aceite em: 28/07/2021 
Viseu: Secção de Educação Matemática da Sociedade Portuguesa de Ciências de Educação, 2008, p. 101-116.

HAMPTON, M. 2010. Reflective Writing: A Basic Introduction. Portsmounth: Department of Curriculum and Quality Enhancement. Disponível em: $<$ http://www2.port.ac.uk/media/contacts-and-departments/student-supportservices/ask/downloads/Reflective-writing---a-basic-introduction.pdf $>$. Acesso em: 18 jul. 2019.

MINÉ, Valdete Aparecida do Amaral. A escrita nas aulas de Matemática: contribuições na formação de professores. In: Conferência interamericana de Educação Matemática, 2011, Recife. Anais... Recife: EDITORA, 2011. p. 1-9.

PASSOS, Cármen Lúcia Brancaglion. A comunicação nas aulas de Matemática revelada nas narrativas escritas em diários reflexivos de futuros professores. Interacções. Lisboa, n. 8, p. 18-36, 2008.

PONTES, Rosana Aparecida Ferreira. Os registros reflexivos como prática de autoria pedagógica. In: Colóquio Internacional Educação e Contemporaneidade, 2011, São Cristovão. Anais... São Cristovão: EDUCON, 2011. p. 1-15.

RADETZKE, Franciele Siqueira. O escrever reflexivo na constituição do Ser Professor. Revista Insignare Scientia - RIS, v.1, n. 3, p. 1-13, set./dez. 2018.

SANTOS, Edilaine Regina dos. Análise da produção escrita em matemática: de estratégia de avaliação a estratégia de ensino. 2014. 156 f. Tese (Doutorado) - Curso de Doutorado em Ensino de Ciências e Educação Matemática, Departamento de Matemática, Universidade Estadual de Londrina, Londrina, 2014.

SANTOS, Edilaine; Buriasco, Regina luzia Corio de. Análise da produção escrita em Matemática como uma estratégia de ensino: algumas considerações.

Educação Matemática Pesquisa, São Paulo, v.17, n.1, pp.119-136, 2015.

SANTOS, Edilaine Regina dos. BURIASCO, Regina Luzia Corio de. A análise da produção escrita em matemática como estratégia de avaliação: aspectos de uma caracterização a partir dos trabalhos do GEPEMA. Alexandria: Revista de Educação em Ciência e Tecnologia, Florianópolis, v. 9, n. 2, p. 233-247, nov. 2016.

SEMANA, Sílvia; SANTOS, Leonor. Porque é importante explicar como pensei: os relatórios escritos na regulação das aprendizagens em Matemática. In: Actas do ProfMat 2008, Lisboa: APM, p.1-13, 2008.

SILVA, Américo Junior Nunes da; PASSOS, Carmen Lúcia Brancaglion. Querido diário: o que dizem as narrativas sobre a formação e a futura prática do professor que ensinará matemática nos anos iniciais. Hipátia - Revista Brasileira de História, Educação e Matemática, Campos do Jordão, v.1, n.1, p. 46-57, dez. 2016.

UHMANN, Rosangela Inês Matos. Estratégias formativas na formação inicial e continuada de professores de Ciências. Revista Insignare Scientia - RIS, v. 2, n. 3, p. 262-269, 2019.

Recebido em: 29/01/2021

Aceite em: 28/07/2021 
UNIVERSITY OF BIRMINGHAM (England). Library Services. A short guide to reflective writing. 2015. Disponível em:

$<$ https://intranet.birmingham.ac.uk/as/libraryservices/library/skills/asc/documents/public/Shor t-Guide-Reflective-Writing.pdf >. Acesso em: 18 jul. 2019. 